\title{
El cuerpo: fundamento de una poética actoral
}

RESUMEN: Este artículo indaga en ciertos procedimientos creativos que, desde el cuerpo, le permiten al actor crear su propia poética. Son operaciones cuyo eje constitutivo es el trabajo con la noción de lo literal, que posibilita el diálogo entre la teatralidad, las sugerencias del director y el texto dramático. Se abordarán centrándose en ejemplos de metodologías usados en la creación de personajes dentro de dos obras, Los empeños de una casa de Sor Juana Inés de la Cruz y La cruzada de los niños de Marco Antonio de la Parra.

Palabras clave: literal, cuerpo, actor

I

Desde hace ya un tiempo, el teatro y las disciplinas artísticas en general son considerados y valorados por el resto de la comunidad universitaria como una forma particular de conocimiento. Sin embargo, todavía queda mucho por avanzar para establecer claramente de qué tipo específico de conocimiento estamos hablando y de cómo este se produce.

El quehacer del artista -y específicamente la actuación- debe ser recorrido como un terreno dispuesto para revelar algunos de los elementos no visibles que componen la experiencia creativa. Como la idea es acercarse a la intimidad del proceso creativo actoral, el objeto de

\footnotetext{
*Daniel Gallo es actor y Licenciado en Artes de la representación. Trabaja como docente en la Escuela de Teatro de la Pontificia Universidad Católica donde realiza cursos de actuación y Verso clásico español. Ha participado en una serie de proyectos de investigación de forma práctica y teórica en la Escuela de Teatro UC y como actor en el teatro UC. Actualmente es Miembro de la compañía de teatro la Calderona. Email: dgallo@uc.cl
} 
estudio es aquí trabajado a partir de la propia experiencia teatral del autor de estas notas. Al compartir estos procedimientos se quiere transmitir un cierto conocimiento respecto de una poética actoral' ${ }^{1}$ la que es velada tras el espectáculo. Así la conceptualización de estos mecanismos intenta establecer a la persona/actor como fundamento de su poética; la experiencia teatral y de vida como punta de lanza de su estrategia creativa.

Siempre hay un procedimiento, un modo de hacer, por sencillo que sea. Cuando se crea algo siempre se procede de alguna forma. Lo difícil es estructurar una noción atingente sobre la forma en que opera ese procedimiento. En un proceso artístico tener conciencia de algo que nos sirve para llegar a un fin es de alguna manera tener noción de ese fin y, en un proceso artístico actoral, este se presenta más como un paisaje borroso que como una imagen completamente delineada.

Para armar sus personajes, los actores no solo se sirven de la aplicación de ciertas técnicas específicas, sino de las experiencias acumuladas a través de los años en el oficio. Es uno de los valores del arte entregar conocimiento a través de la experiencia a quien lo realiza y a quien lo percibe. Así lo comprueba la idea de que se actúa mejor a medida que se envejece. Idea digna de problematizar y al mismo tiempo cargada de sentido, ya que emana muchas veces desde la misma gente de teatro. Otra creencia popular del gremio que nos habla de la importancia de la experiencia, es que, cualquier otra actividad que se realice en la vida, independiente que pertenezca al ámbito de lo teatral, servirá para tu desarrollo como actor, una especie de batería de herramientas que se acopian en un saco. Un mal de Diógenes teatral; siempre habrá oportunidad de aplicar esa experiencia en algún montaje.

La experiencia, entonces, actúa modificando la forma de articular los conocimientos actorales técnicos y posibilita la aplicación de esos mismos conocimientos técnicos en diferentes procesos creativos. Lo difícil de organizar estas experiencias en alguna metodología es que eso sería escribir una especie de manual de actuación o una guía técnica y lo que se busca en este artículo es develar un modo de hacer, dar cuenta de una posible poética resultado de la práctica y establecer que cada actor es dueño de una.

Interesa, entonces, compartir este procedimiento actoral escénico y creativo que ha guiado mi trabajo durante los últimos espectáculos en los que he participado y que me ha ayudado a afianzar una perspectiva artística cada vez que enfrento un proceso de montaje. Si lo 
pudiéramos definir en términos conceptuales me referiría a este fenómeno como las distintas formas de asumir lo literal del texto dramático y las propuestas de dirección e incorporarlo al trabajo escénico. Se trata entonces, de reflexionar en torno a las imágenes que este término evoca y arrastra.

Es evidente que el término literal inmediatamente nos traslada al mundo de la palabra escrita.

Literal.

(Del lat. litter lis).

1. adj. Conforme a la letra del texto, o al sentido exacto y propio, y no lato ni figurado, de las palabras empleadas en él.

2. adj. Dicho de una traducción: En que se vierten todas y por su orden, en cuanto es posible, las palabras del original.

3. adj. Que reproduce lo que se ha dicho o se ha escrito.

4. adj. En la transcripción de una escritura alfabética a otra lengua, que procede letra por letra.

5. adj. Fil. y Mat. Dicho de un concepto o de una magnitud: Que se expresa con letras.

(R. A. E. versión en línea)

La palabra literal se mueve incuestionablemente en el campo de la utilización, análisis y producción de trabajos de escritura como medio de expresión. Más específicamente el término nos acerca al mundo de la traducción ${ }^{2}$ de textos.

Posiblemente no es un error pensar en el acto de traducir cuando intentamos especificar este fenómeno actoral; trasladar lo literal que escribe el dramaturgo o lo que plantea el director, hacia la puesta en escena es en esencia hacer una traducción.

Lo sustancial es que queremos extrapolar el término literal de su esfera de la palabra escrita para llevarlo hacia el terreno de lo teatral, posicionándolo como un mecanismo actoral que produce un resultado escénico particular. ¿Qué es entonces esto de lo literal y qué dimensiones alcanza en el trabajo expresivo del actor? 
Se adopta el término literal por razón de inmediatez, es decir, por la necesidad de nombrar un fenómeno que ocurre a nivel personal y poder transmitirlo como conocimiento; valorar la experiencia del artista e insertarla a nivel académico. Es así como la adopción del término más allá de la intención de acuñar un nuevo concepto, de sumar una palabra más a las muchas que usamos para analizar la creación, se usa para delimitar una imagen de lo que se quiere transmitir. Y aun así, literal no es un término gratuito. No se aplica como moneda de cambio, no es canje. Si bien puede parecer una reducción caprichosa, también es cierto que refleja lo que busco y en la palabra misma pujan ciertos componentes personales relacionados a la forma de crear los personajes, quienes trasladan esta visión a la puesta en escena.

Cuando una persona asiste al teatro se entiende, al mismo tiempo, que lo hace para ver teatro. Esta sencilla idea trae una pregunta esencial para el trabajo de puesta en escena. ¿Qué es entonces lo que ve el espectador? No creo que la respuesta provenga de la idea heredada del concepto, "donde el director se convierte en el responsable 'oficial' del [...] espectáculo" (PAVIS, 2008, p. 362).

Por el contrario la respuesta debe provenir de cada uno de los integrantes del equipo creativo que pone en escena. El actor, por tanto, debe plantear mediante su trabajo un punto de vista que le permita apoderarse de esa puesta en escena, convirtiéndose también en un responsable del espectáculo, al preguntarse ¿qué es lo que permito que vea el espectador? ¿Cuál es el punto de vista que quiero darle a este personaje?

La aplicación del término como procedimiento actoral aparece cuando me apropio, de manera literal, de ciertos estímulos entregados por el texto o por las propuestas del director. Hacer una selección de elementos que entregan un punto de vista, una interpretación propia del personaje a la puesta en escena. Sin embargo y siguiendo a Eco, podría yo decir que "[n]adie está más a favor de abrir lecturas que yo, pero el problema es, aun así, establecer 'lo que se debe proteger para abrir, no lo que se debe abrir para proteger'" (ECO, 1990, p. 43).

La cita de Eco, sacada de un texto sobre análisis literario, nos permite desarrollar esta idea de la protección de sentido que aporta el mecanismo actoral de lo literal, al hacer una analogía entre un discurso escrito y un espectáculo teatral. Proteger escénicamente quiere decir trasmitir de forma efectiva los elementos mínimos para comprender el punto de vista del (los) creador (es) del montaje o personaje. 
Un ejemplo. En el año 2012 montamos la obra Los empeños de una casa de Sor Juana Inés de la Cruz en la que existen dos criados: Celia y Castaño, quienes a lo largo de la obra establecen una relación que termina en matrimonio. La puesta en escena ${ }^{3}$ contemplaba una serie de cambios escenográficos que eran realizados por dos integrantes del elenco -Lilian Vásquez y Daniel Gallo- los criados. Para reforzar esta relación amorosa que se establecía en algunas escenas del texto, se sugirió que el erotismo entre ellos fuera progresando a través de los encuentros que se producían en estos cambios. Así nació la idea de que Castaño le regalara algo a Celia, algo importante para él; le regalaba comida, que para efecto de un criado es un acto de amor. Una manzana. De esto surgió una improvisación que luego de ser ensayada funcionaba perfectamente como situación escénica.

No obstante pensé que faltaba algo para retratar más fielmente el universo de los criados de una comedia, que, en general, tienen necesidades más básicas y si el fin de estos encuentros amorosos era el matrimonio, el regalo debía retratar ese universo amoroso más elemental. Entonces el regalo tenía que ser algo más erótico sexual. Ahí pensé cambiar la comida por una serie de juguetes sadomasoquistas para proponer en la escena, sin embargo, en toda puesta en escena existe una estética que respetar. Había que encontrar un regalo acorde a la estética del montaje y que, al mismo tiempo, cumpliera con el objetivo de describir el mundo del personaje. Castaño, entonces, le regaló un plátano en vez de una manzana a su futura esposa. Así la idea de lo literal sexual se convirtió en una imagen icónica del pene.

Teniendo presente la cita de Eco cabe preguntarse ¿qué elementos quiero proteger para darle sentido al trabajo?

Como no podemos manipular los contenidos que transporta la persona que es receptor de la obra, esta interpretará con libertad esa creación de la que es testigo. Las interpretaciones se abren a cada espectador, a sus conocimientos, su historia, su vida. Sin embargo, hay ciertos elementos que cada creador quiere proteger de su obra, justamente para poder abrir la interpretación de la misma. Asumir en el cuerpo propio del actor lo literal del texto o la indicación de dirección y establecerlo como procedimiento escénico permite, al menos como punto de partida, mantener estos elementos del texto dramático y de la puesta en escena como una especie de parámetro de las posibles interpretaciones que existan del espectáculo. Por ejemplo, el plátano quiere, en palabras de Eco, proteger mi visión del sentido evidente y sexual del 
personaje. La idea de rescatar lo literal pujó un tipo de referente que proviene de una visión de mundo que contribuye a construir esta poética actoral.

El plátano se convirtió en un objeto literal que generó una serie de acciones dramáticas que surgieron de su uso: presentado por Castaño, encontrado por Celia, mascado por Castaño y llevado por la criada a su habitación. En otra escena, Celia aparecía con el plátano mascado, se enteraba que el plátano era de él, se lo lanzaba y por último los criados se escondían tras unos muebles y se besaban. Es decir, este objeto producto de la interpretación literal, movilizó acciones eróticas evidentes de los criados, que produjeron juegos escénicos que nutrieron creativamente la puesta.

El mismo Roland Barthes da un ejemplo preciso de este tipo de literalidad cuando habla de la pieza del dramaturgo Arthur Adamov: "[...] el billar eléctrico de Ping-Pong [...] es un objeto literal, cuya función consiste en engendrar situaciones por su misma objetividad" (BARTHES, 1980, p. 53).

Tanto el billar eléctrico como el plátano, a diferentes niveles, son objetos que producen situaciones dramáticas; uno a nivel dramatúrgico, otro a nivel actoral. Ambos movilizan la acción de una forma inmediata al momento de su aparición. Es el objeto mismo el que por su condición provoca situaciones escénicas.

Existe también otra manera de aplicar esta idea de lo literal transformando el mismo cuerpo del actor en un objeto literal que produzca situaciones escénicas de la puesta en escena.

II

Pero no solo de esa obra pueden extraerse ejemplos que permitan la visualización de lo que se expone. La Cruzada de los Niños de Marco Antonio de la Parra es una obra dramática construida por siete monólogos de niños que relatan haber sufrido algún tipo de abuso o violencia. La puesta en escena del año 2005 rescató cuatro de esos monólogos en el siguiente orden: el expósito (Daniel Gallo), la niña que vendía flores (Manuela Martelli/lgnacia Agüero), el niño obrero (Germán Pinilla) y el niño malherido (José Manuel Aguirre). Yo debía interpretar al personaje del expósito que, según el texto, es un niño lanzado a las riberas del río Mapocho ${ }^{4}$ justo en el momento de nacer. Un niño sin bautizar, sin alimentar, que se autonombra Clavel, que es testigo de un allanamiento y a quien los recuerdos atormentan incluso después de su muerte, ya que nos habla desde el purgatorio. 
Con estas características, interpretarlo es algo más que un desafío. Y, a pesar de todas las exigencias, lo que me preocupaba era algo inicial: ¿cómo interpretar a un niño? Crear un cuerpo en coherencia con el texto -niño y expósito- que, además, interactúe en sintonía respecto del resto de los actores y elementos que componen el espectáculo. En definitiva, un cuerpo que fuese capaz de mediar las necesidades estéticas del texto dramático y de la puesta en escena y que resolviese la construcción física del personaje.

Según explica Adolphe Appia, “la conformación escénica deriva de la jerarquía música-cuerpo-espacio, donde música y espacio solo podrán entrar en relación a través de la mediación del cuerpo" (SÁNCHEZ, 2004, p. 173). La reflexión de Appia se desprende del impulso renovador de la teoría wagneriana sobre la gesamtkunstwerk u Obra de arte total donde el teatro es la síntesis de todas las artes. Síntesis en la que el actor, según Appia, es el encargado de integrar todos los elementos previstos en la puesta en escena. Hacer esto de manera consciente permite potenciar el trabajo actoral.

La directora de La cruzada... para poder llevar a cabo el montaje propuso diferentes estrategias creativas de entre las cuales me interesa relevar dos para desarrollar la idea de la transformación del cuerpo en objeto literal.

El texto de Marco Antonio de la Parra está construido con ideas cercanas al teatro épico planteado por Brecht, en donde se pretende estudiar más que moralizar. El autor no quiere retratar miméticamente el mundo de estos personajes, para lo cual recurre a dos estrategias, las que son utilizadas con un sentido didáctico para distanciar el relato de los personajes. Primero, los personajes no viven en poblaciones cultural o económicamente periféricas, sino que habitan una especie de limbo, apelando desde allí, incluso con sus palabras a un universo absolutamente reconocible que no sería prudente negar. Segundo, los monólogos están escritos de forma independiente de manera que no existe diálogo entre los personajes. Por tanto, la observación de personas, espacios y situaciones reales, permitiría crear la situación dramática en la que estos personajes monologantes se relacionan otorgando un contexto analógico a esta idea de purgatorio.

No obstante, la realidad con la que nos encontramos en nuestro recorrido investigativo previo al trabajo sobre la escena, por las calles de Santiago, nos mostró que estas personas a las que hace referencia el texto se camuflan con el paisaje de la ciudad, naturalizándose, haciendo que los propios habitante de la ciudad pierdan conciencia de que aquellos existen. 
¿Cómo es posible, entonces, usar de referente algo que nos es in-visible? La respuesta está en la paradoja, explicada por María José Contreras, que se presenta cuando se intenta una definición de cuerpo: "Por un lado [el cuerpo] es lo más cercano e íntimo a nuestra experiencia pero por otro lado [nos] resulta extraño... ¿Cuándo aparece el cuerpo?... En general... cuando 'falla', 'duele' o 'se equivoca'" (2012, p. 15).

Los referentes que teníamos de estos niños a través de los documentales y de la observación real, nos hablaba de un tipo de cuerpo evidentemente deteriorado; su piel, sus ojos, su cara, sus palabras, su mirada, su actitud general; todo un cuerpo producto de una vida desgastada. Esos cuerpos dolorosos eran los que debíamos construir; cuerpos que no responden a la voluntad del propio dueño, cuerpos golpeados, cuerpos atropellados, cuerpos prostituidos; cuerpos que para nosotros los actores solo se percibían a través de la composición de posturas incómodas que permitían hacer consciente la presencia del mismo.

Paralelamente a la observación, y como otra estrategia de montaje, la directora, nos hizo trabajar de manera lúdica con diferentes verbos e interpretarlos, primero físicamente, o sea llevarlos al cuerpo. El trabajo, metodológicamente hablando, fue planteado de esta manera: a) se creó una lista arbitraria de verbos obtenidos de diferentes fuentes, desde internet, de un libro de verbos, aportados por los actores, etc., b) estos se escribieron en papeles individuales y se colocaron en un montón en el centro del escenario, c) así los actores escogían al azar diferentes verbos, luego d) se jugaba a representar el verbo, con el cuerpo, de diferentes maneras, desplazándolo en diferentes niveles, diferentes velocidades y diferentes formas. Luego se repetía el mismo procedimiento con otro verbo, hasta crear un abanico amplio de acciones, que cada actor se encargaba de seleccionar. Así pasábamos largas horas de ensayo articulando y produciendo estos verbos de manera corporal.

A este trabajo seguía una segunda etapa que consistía en incorporar la voz. A ese cuerpo que se mueve con determinado verbo, se le pide entonces emitir un sonido que sea coherente con el esfuerzo y la forma respecto del movimiento físico que se está generando.

Finalmente, se superpone el texto dramático en la pauta física-sonora. Al incluir la emisión del texto en esta dinámica azarosa de los verbos, se elimina el prejuicio que el actor podría tener respecto del personaje. Basta decir el texto, por ejemplo, siendo un paño que limpia para darse cuenta de que es casi imposible de que exista una idea preconcebida sobre esta mezcla. 
Pero lo que me permitió proyectar una posibilidad escénica en esta metodología fue cuando se nos indicó ser ${ }^{5}$ el verbo. ¿Cómo puedo ser el verbo barrer, correr, limpiar, calcular, inyectar, etc.? Y lo que es más paradójico, lingüísticamente hablando, ¿cómo puede ser el verbo ser?

Esta indicación tenía absoluta resonancia con esta idea de lo literal; el cuerpo como un objeto literal en acción. De alguna manera esta encarnación del verbo en el cuerpo solo se concreta a través de lo literal que despliega el verbo en el cuerpo del actor.

El trabajo de hacer que sean los verbos, propuesto por la directora, es tan concreto que el intérprete solo se concentra en absorber e interpretar el verbo en su cuerpo, dejarse invadir por la dinámica que la ejecución de ese verbo propone y no se entrampa en generar simbolismo ni en significar. Se convierte en un cuerpo-objeto literal que tiene como objetivo producir posibilidades de relación con los otros actores, tantas como existan en la cabeza del intérprete. Para seguir en esta línea, tomemos el verbo limpiar, que lo primero que genera es movimiento: imaginen -se nos decía- ser limpiar con el cuerpo. Si bien la indicación suena extraña, solo era necesario dejarse llevar por el sentido lúdico que la misma frase propone para que funcione; imaginen moverse siendo un paño que limpia, siendo una escoba, siendo un trozo de pañuelo con encaje, etc. Otra posibilidad de ser el verbo limpiar se produce cuando pienso en ser la basura que la escoba barre o la mancha que el paño limpia o un ventilador que limpia el aire, un chorro de agua que limpia el piso, un algo que limpia otra cosa... Al sumergirse en esta dinámica, las posibilidades de improvisación se multiplican casi al infinito.

Lo anterior resulta muy interesante si uno lo compara con lo que ocurría paralelamente cuando íbamos a observar a los niños de la calle que vivían bajo el puente Bulnes ${ }^{6}$. De hecho, esos niños con los que compartimos no hacían juicio de sí mismos. Su forma de relacionarse era a través de saciar necesidades inmediatas como el aburrimiento, el frío, el hambre. Simplemente habitaban la realidad en la que estaban; la calle, que para nosotros constituía, prejuiciosamente, una amenaza, para ellos era su hogar.

Nosotros también habíamos encontrado en los ensayos nuestra forma de relacionarnos, mezclando estímulos de verbos con sus interpretaciones físicas y el texto. Los cuerpos de nuestros personajes se construían de su presente inmediato sin ideas preconcebidas de la desdicha que traía la ficción del montaje. 
Sin embargo, me seguía incomodando una idea respecto a la construcción del cuerpo del personaje. ¿Cómo hacer constituir, configurar teatral y creativamente, el cuerpo del niño expósito? Las historias que narraban los monólogos eran de tal dureza, que cualquier decisión escénica debía respetar esa característica. La realidad observada aportaba un poco de esa dureza, pero no me solucionaba la constitución creativa del cuerpo del niño. ¿Qué tan posible era acercarme a experimentar la realidad del cuerpo de un niño abandonado?

Aquí aparece nuevamente la apropiación, por parte del actor, de un elemento literal como procedimiento escénico actoral, al volver a investigar en el texto ${ }^{7}$. El texto dramático es el punto desde el que emanan muchas de las provocaciones que desencadenan el trabajo de puesta en escena. El actor, entonces, debe sumergirse en ese universo dramático que el texto le impone y propone. "Si el actor está dispuesto a construir su personaje tendrá que absorber todo lo que rodea al personaje" (EINES, 2007, p. 36). Intuía, entonces, que lo que debía hacer era seleccionar algo de lo señalado en el texto, algún elemento descrito, e insertarlo directamente en la construcción de ese cuerpo, transportando de forma literal la selección hecha del texto al contexto escénico.

¿Cómo es un niño expósito literalmente?

El diccionario me dio esto como definición: expósito, ta. (Del lat. expos tus, expuesto) /adj. Dicho de un recién nacido: Abandonado o expuesto, o confiado a un establecimiento benéfico.

Entonces para asumir escénicamente esta descripción hay que traducirla de forma literal, pensé: mi niño expósito murió porque lo dejaron en las riberas del río Mapocho, por lo tanto el personaje entraba a escena con su vestuario, literalmente, mojado. Su primer texto era "ahí quedé tirado", por lo tanto la primera acción que realizaba era acostarme, literalmente, en el suelo. Asumí que había muerto de hipotermia por eso al decir los primeros textos, literalmente, tiritaba de frío. Estas acciones sencillas, casi obvias del proceso creativo, pretenden evidenciar cómo la literalidad va marcando el camino que lleva a construir esa imagen final que se tiene del personaje.

Con todo, el concepto niño expósito, no estaba construido escénicamente en su totalidad: “El expósito es un niño que [...] no tiene pelos. Tampoco se le da la oportunidad de mamar. Esta desprotegido por fuera, desprotegido por dentro" (GALLO, 2006, p. 14). 
¿Cómo entonces, a través de lo literal, se puede reproducir escénicamente la idea que tengo de niño abandonado? La forma que encontré para someterme a esa desprotección y que, además, construiría la imagen de un niño, fue depilarme casi por completo. En verdad, lo que más me importaba era exponer la zona púbica. Esto no solo como acto personal de indefensión y exposición, sino porque lo que diferencia un niño de un adulto o de un adolescente es su zona púbica vacía de vellos. Sintetizar la idea de niño expuesto con este sencillo recurso, creando un cuerpo cuya función dramatúrgica no fuera simbolizar ni instaurar la imagen exterior de un personaje indefenso, sino crear un cuerpo que se hiciera presente producto de la incomodidad. En definitiva era una decisión que solo quería darle al cuerpo la oportunidad de ser al igual que el ejercicio con los verbos, satisfaciendo una necesidad de apropiarse del proceso creativo producto de una poética actoral.

\section{III}

Todo esto puede relacionarse con el procedimiento que el dramaturgo argentino Rafael Spregelburd utiliza y que llama "la huida del símbolo":

Un material artístico ni siquiera necesita ser verdadero para validar su existencia. ¿Por qué es esto? Porque en vez de proponerse conformar un símbolo convencional de lo real, busca constituirse como un objeto "agregado" a lo real [...] No es signo de otra cosa, es la cosa. Huir de toda posible lectura simbólica es el primero, y quizás el único, de los procedimientos que manejo conscientemente. (SPREGELBURD, s/a, p. 2) ${ }^{8}$.

La depilación provoca acción, cambia la sensación física del actor, entrega cierta extrañeza en el momento de actuar y que se corresponde con la extrañeza del personaje. Se funde, en una imagen, lo literal de un niño con el cuerpo del actor. ¿El resultado? Un adulto lampiño, al que otros personajes cambiaban de ropa y cuidaban en sus primeras y últimas horas de vida. Una imagen sugestiva que se aportaba al colectivo, al texto espectacular, a las impresiones sugerentes y creativas de la obra.

Asumir escénicamente lo literal escrito en el texto, (1) lo crea y (2) lo protege. En este caso específico, el hecho de la implantación literal de la depilación de la zona púbica: 1) crea al niño expósito porque hace referencia directa a la imagen de un bebé real y, además, establece la diversidad del personaje con respecto a los otros niños; todos son niños violentados, pero solo 
un niño es expósito. Y 2) protege el sentido del texto porque evidencia que los crudos hechos descritos por el texto son vividos por personajes que son efectivamente niños.

Desde mi perspectiva esta dualidad construye el discurso de la puesta en escena.

He ido al texto para encontrar una solución al problema actoral. La respuesta al problema fue traducir literalmente el texto dramático y convertirlo en un hecho teatral; asumir la imposición o autoimposición del texto.

Esta afirmación genera un interesante debate; si el texto es una imposición, ¿dónde queda el trabajo creativo y la poética del actor -que impulsa este escrito- en la puesta en escena? Entre las cargas de la escritura dramática y lo establecido por el director, falta el elemento del actor para componer el triángulo básico de puesta en escena; un área compleja que conecta dos puntos de tensión. No es mi propósito establecer una relación antagónica entre actor, dramaturgo, director, pero cuando hablamos de poner en escena es el intérprete el que permite el desarrollo de los otros dos.

El actor absorbe, resiste, conecta y relaciona el impacto de lo que el dramaturgo escribe con lo que el director propone y viceversa. Se sitúa en un punto de contacto donde se instala la tensión que permite desplegar la fuerza creadora de ambas figuras y alzar la puesta en escena. En él se manifiesta el proceso creativo justo en el instante en que cada vez ocurre la escenificación. Lo que se entiende por personaje es la articulación de toda la información del espectáculo, mezclada y filtrada en el cuerpo del actor bajo las reglas de su poética. Esta poética funda su trabajo.

Si hablamos del proceso personal del director cuando visualiza la puesta en escena, al igual que del proceso que le permite al dramaturgo proyectar imágenes en el texto cuando escribe, diremos que estos se detienen justo antes de convertirse en el fin: texto dramático y puesta en escena. Sin embargo, en el trabajo de la interpretación, estos procesos íntimos son el soporte mismo del trabajo creativo, ya que son estos quienes articulan bajo la poética propia del actor los otros materiales para darles un sentido; la creación actoral del personaje no tiene cierre, siempre es nuevo, siempre renace, porque se organiza en el presente en el que se realiza.

Al ejercer esa libertad de dar sentido a las imposiciones, nacen las estrategias propias; la poética y el sello personal del actor. 
Estas imágenes internas de las que el actor se vale para acoger estas diferentes imposiciones del texto y la puesta en escena no se expresan, pero están presentes en todos y cada uno de los momentos del espectáculo y tienen por principal objetivo entregar consistencia al trabajo de interpretación. Materializa al personaje en la puesta en escena ¿de qué manera? Por ejemplo, cuando como actor tomo una decisión, como es decir un texto o hacer una acción, para dilatar, profundizar, dar sentido a ese texto o esa acción, debo, al mismo tiempo, ser consciente de que existe una serie de posibilidades que no tomé. El texto y la puesta imponen sus propias características productivas, pero el actor, de esta manera, transforma aquello en una decisión libre; solo si doy cuenta, también del universo omitido, tengo libertad para dominar el mundo creativo que elegí, permitiéndome la apropiación de la evolución dramática de mi personaje.

Estos procedimientos, que transforman las imposiciones en decisiones, son personales y son en esencia distintos porque articulan información diferente en cada espectáculo. Todos los artistas, independiente de la disciplina artística en la que trabajen, hacen hincapié sobre la forma y cada texto y puesta en escena, en el caso del teatro, requiere de maneras distintas para ser abordada. No hacerlo involucra aplicar una fórmula y esto semeja, de algún modo, a hacer lo mismo.

Apropiarse de lo literal de un texto se presenta entonces como un recurso personal, es develar un proceso mental del actor para abordar el texto y plasmarlo en la puesta en escena.

¿Proceso mental del actor? Sí. Si uno se pregunta el porqué la gente hace lo que hace es algo que nunca se sabrá con certeza, incluso si esa persona lo dice. Por ejemplo ¿qué pasa dentro de la cabeza de un tipo que mata a otro? Razones podemos encontrar y muchas. Pero quien experimenta el proceso real es la persona que realiza la acción y cómo se articula eso, nunca lo sabremos. En el mundo de la actuación, ocurre un fenómeno similar. ¿Quién sabe lo que le sucede al actor en el momento preciso en que ocurre la actuación? Es un momento íntimo que responde a un universo personal y que no importa develar en la puesta en escena. Es un espacio donde se funde actor y personaje. El universo del actor le presta elementos al personaje para que pueda articularse en escena o si se prefiere, el actor articula elementos para conformar el personaje. El actor le da consistencia a su personaje al justificar las palabras del dramaturgo y las propuestas del director. La manera en la que se proyecta este trabajo es la 
apropiación de la puesta en escena; un entendimiento total del espectáculo. El actor materializa lo que más llama su atención; plasma su visión de mundo.

Lo literal es una forma subjetiva para justificarme objetivamente sobre el escenario. De hecho literal es una palabra que funciona preferente y quizá exclusivamente en mí.

Todo es susceptible de ser convertido en literal. ¿Bajo qué criterio se deben seleccionar estos elementos para producir la literalidad? Bajo el criterio de lo que a cada uno le interese. Para entregar algunas pistas sería posible servirse de un ejemplo, dado por el dramaturgo David Mamet, en relación a otro concepto de la actuación, la concentración:

La concentración es como el agua. Siempre busca su nivel, siempre irá a parar a la cosa más interesante que tenga alrededor. El niño cogerá la caja de cartón antes que el regalo que contiene, y como dijo Freud, un hombre con dolor de muelas no puede estar enamorado. [...] Ejerciten su poder en la elección que hagan. Hagan una elección convincente [para ustedes] y no les costará nada realizarla (MAMET, 1997, p. 96).

Así como la concentración, la búsqueda de lo literal funcionan analógicamente: transformar en escénico lo literal del texto que te entretenga, lo que entiendas, lo que quieras proteger de tu interpretación, los elementos que marcan tu punto de vista sobre el personaje y articúlalos bajo parámetros propios. No vale la pena cuestionarse si lo que se eliges es correcto o no, es evidente que para dar luz a ciertas zonas se oscurezcan otras.

Es deber, el saber que cada actor es portador una poética por el hecho de ser un medio; validar su historia, sus experiencias de vida y teatrales, sus referentes, su cuerpo, todo lo pasado, lo presente y lo imaginado para cultivar esa poética. Cualquier cosa que exista en el mundo del actor ha de usarse como material creativo. Incentivar la creación de mecanismos escénicos que se proyecten en la independencia creadora del actor. Las reflexiones que más me han ayudado a entender la actuación, provienen de disciplinas que no son el teatro; finalmente, parece, la vida se trata de lo mismo hagas lo que hagas.

Estos apuntes, con no pocos ribetes de divagaciones, han intentado transmitir una perspectiva artística que se define de la misma forma: someter bajo reglas propias los elementos que se ponen a su disposición. Lo literal, tal cual lo he presentado, es un procedimiento propio de cómo entiendo un cierto nivel de trabajo y producción actoral, en cuyo centro se encuentra siempre lo corporal como pivote vivo de acción y reacción creativa. 


\section{Notas}

1 Hablamos de mecanismos pertenecientes a la intimidad de cada intérprete. Conjunto de ideas y reglas propias.

2 Término convencional que se usa para designar la actividad de sustitución de un texto en lengua de partida por un texto equivalente en lengua final. Sabemos que existe variada terminología para especificar ese trabajo (traslación, versión, trasposición, interpretación, re-expresión, etc.) que no es atingente en este análisis.

3 Puesta en escena realizada por la compañía de teatro La Calderona con dirección de Macarena Baeza en el año 2012. Temporada en el centro cultural GAM, Santiago de Chile. Selección festival internacional de teatro clásico de Almagro, España, año 2012.

4 Río que cruza la ciudad de Santiago de Chile.

5 Atributo adjudicado a la entidad capaz de definirse a sí misma.

6 Puente del sector poniente de la ciudad de Santiago y que cruza el río Mapocho. En ese lugar se encuentra un monumento homenaje a víctimas de la dictadura militar de 1973.

7 En el caso de perder el rumbo en la creación de un personaje y existiendo un texto dramático, se suelen encontrar en la obra casi todas las respuestas; ese es el universo al que hay que remitirse.

8 El texto de Spregelburd todavía no se encuentra publicado.

\section{Referencias}

ECO, Umberto. Los límites de la representación. Trad. Helena Lozano. Barcelona: Ed. Debolsillo, 2013.

EINES, Jorge. Alegato a Favor del actor. La imaginación es el cuerpo. Barcelona: Ed. Gedisa, 2007.

BARBA, Eugenio; SAVARESE, Nicola. Anatomía del actor: diccionario de antropología teatral. México: Ed. Gaceta, 1988.

BARTHES, Roland. El grado cero de la escritura. Trad. Nicolás Rosa. México: Ed. Siglo Veintiuno, 1983.

BARTHES, Roland. Mitologías. Trad. Hector Schmucler. México: Ed. Siglo Veintiuno, 1999.

CONTRERAS, María José. Introducción a la semiótica del cuerpo: Presencia, enunciación encarnada y memoria. Cátedra de artes, n. 12, p. 13-19, 2012.

DUARTE, Coca. El proceso de creación teatral. Primeras aproximaciones. Teatro/Celcit, Revista de Teatrologían técnicas y reflexión sobre la práctica teatral, n. 37-38, p. 115-125, 2010. Publicación digital.

DUBATTI, Jorge. Introducción a los estudios teatrales. Buenos Aires: Atuel, 2012.

DUBATTI, Jorge. El teatro sabe: la relación escena/conocimiento en once ensayos de teatro comparado. Buenos Aires: Atuel, 2005.

GALLO, Daniel. El cuerpo expósito de Abraham. Cuadernillo pedagógico obra La cruzada de los niños, Santiago, Chile, Teatro UC, septiembre 2006.

GRASS, Milena. La investigación de los procesos teatrales: manual de uso. Santiago: Ed. Frontera Sur, 2011. 
GRASS, Milena. La investigación de los procesos de creación en la Escuela de Teatro UC. Apuntes, n. 123-124, p. 206-208, 2003. PAVIS, Patrice. Diccionario del teatro: Dramaturgia, estética, semiología. Trad. Fernando de Toro. Buenos Aires: Ed. Paidós, 1980. PAVIS, Patrice. Diccionario del teatro: Dramaturgia, estética, semiología. Trad. Jaume Melendres. 3ra reimpresión. Buenos Aires: Ed. Paidós, 2008.

PAZ, Octavio. Traducción: literatura y literalidad. Segunda ed. Barcelona; Tusquets Editores, 1981.

SÁNCHEZ, María José. El cuerpo como signo. Madrid: Ed. Biblioteca Nueva, 2004.

SARRAZAC, Jean-Pierre (dir.) Léxico del drama moderno y contemporáneo. México: Paso de Gato, 2013.

SPREGUELBURD, Rafael. Procedimientos. s/l: s/e, s/a. 